\title{
Hereditary angioneurotic oedema: an unusual cause of recurring abdominal pain ${ }^{1}$
}

EDWARD J. FELLER, HOWARD M. SPIRO, AND LEONARD A. KATZ

From the Division of Gastroenterology, Department of Medicine, Yale-New Haven Hospital, New Haven, $\overrightarrow{\vec{\omega}}$ Connecticut, Veterans Administration Hospital, West Haven, Connecticut, and the E.J. Meyer Memorial Hospital, Buffalo, New York, USA

SUMMARY Two patients with hereditary angioneurotic oedema, a condition characterized by repeated episodes of abdominal pain and oedema, and by an absence of complement- 1 esterase inhibitor activity in the plasma are presented in detail. Both underwent multiple surgical procedures before the diagnosis was established. Abdominal pain is often the pre- $\mathbb{\mathscr { D }}$ senting complaint, and although a complete history will usually lead to the proper diagnosis, $\vec{\varphi}$ cases in which the family history is not clear can present a diagnostic dilemma. Characteristic $\stackrel{\supset}{\circ}$ radiological demonstration of localized intestinal oedema will only be obtained if studies are performed early during the acute attack.

Hereditary angioneurotic oedema is an autosomal dominant trait characterized biochemically by low serum complement-1( $\left.C^{\prime} 1\right)$ esterase inhibitor activity, and clinically by recurring episodes of abdominal pain and non-inflammatory localized oedema. Although the major symptom is recurrent severe abdominal pain, the condition is rarely recognized by gastroenterologists and there are few references to it in leading textbooks of gastroenterology. Yet reports of this condition can be traced back to 1733 (Barnett, 1948). It was first clearly described by Quincke in 1882, and its genetic aspect noted by Osler in 1888. Although scattered case reports and reviews appeared during the first half of the 20th century (Landerman, 1962), interest in the disorder slackened until the 1960 s when the identification of specific biochemical defects led to a 'rediscovery' of hereditary angioneurotic oedema (Landerman, Webster, and Ratcliffe, 1962; Donaldson and Evans, 1963). The surfeit of cases reported around the turn of the century, and the 1966 report of Donaldson and Rosen that in three years they noted more than 100 patients with this condition, suggest that hereditary angioneurotic oedema is more common than most physicians recognize.

Two patients, each from different families and each with a characteristic history, present an

Received for publication 11 June 1970.

${ }^{1}$ Requests for reprints should be addressed to: Howard M. Spiro, 333 Cedar Street, New Haven, Conn., 06510, USA. opportunity to review the disorder with emphasis $\frac{\circ}{\otimes}$ on its gastrointestinal manifestations.

\section{Case 1}

M.Z., a 35-year-old female school teacher, has had recurring attacks of abdominal soreness since childhood. The episodes have remained similar throughout the years, and she feels entirely well between episodes. Each episode 운 begins with an increasing sense of nausea and $\rightarrow$ soreness, usually in the lower abdomen bilaterally and is occasionally accompanied by several loose $\stackrel{N}{\circ}$ bowel movements. The nausea gradually increases in severity and may be associated with O $^{-}$ vomiting. She lies very still as movement provokes $\omega$ vomiting. The attacks last from 10 to 24 hours and then slowly subside. During an attack the 0

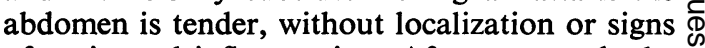
of peritoneal inflammation. After an attack she feels tired, but otherwise well, and by the next day $\frac{T}{T}$ is completely well. She has noted no clear-cut $\frac{O}{\mathbb{D}}$ precipitating cause and no definite relief with a $\stackrel{\odot}{\stackrel{\oplus}{+}}$ variety of medications. There has been some $\stackrel{\square}{\square}$ tendency, however, for the attacks to occur at times of menstrual periods. The episodes occur as $\delta$ frequently as once a week and as rarely as once every three months. Her general health has remained good and her weight has been stable. 
She has undergone two operations. In 1954 a presumptive diagnosis of regional enteritis led to an ileal-colonic bypass; biopsy showed mild mucosal inflammation and submucosal oedema of the terminal ileum. Mesenteric lymph nodes were enlarged and hyperplastic. In 1965 again a presumptive diagnosis of regional enteritis and the failure of prednisone to eliminate attacks led to excision of the excluded terminal ileum and right hemicolon, and an ileotransverse colostomy was performed. Pathological examination of the ileum and colon revealed only serosal fibrosis: the mucosa was unremarkable and there was no evidence of regional enteritis.

Since childhood the patient has had infrequent recurring episodes of swelling involving the hand, face, neck, and posterior pharynx which have required hospitalization on three occasions. The swelling begins in a localized area, such as an arm, and gradually extends; after 12 to 24 hours, the swelling subsides. There is no itching, burning, or redness. No specific exciting causes have been recognized. Neither epinephrine nor corticosteroids have been of benefit. The abdominal symptoms usually occur without oedema elsewhere. The patient's father had several episodes of swelling involving only his hand, usually after local trauma. Neither her mother, brother, nor two children have any history of episodic swelling or of abdominal pain.

In September 1967 a barium meal during an attack of abdominal pain revealed marked oedema of the proximal small intestine and

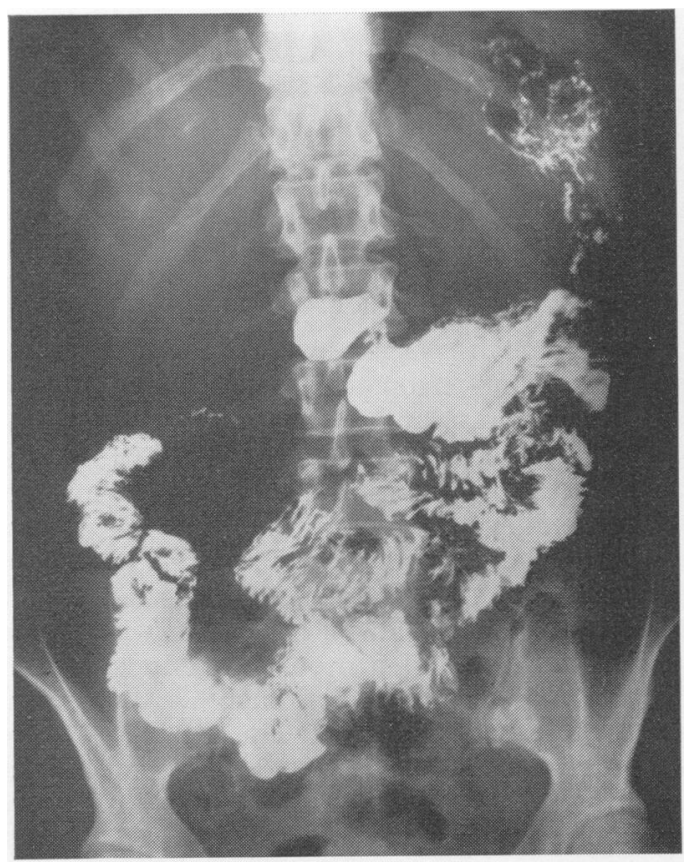

Fig. 1 Barium swallow in patient 1 during an acute episode of abdominal pain demonstrating small bowel oedema. delayed emptying of the stomach (Fig. 1). The small bowel was normal when studied during an asymptomatic interval (Fig. 2). Serum complement-1 esterase inhibitor activity studied in the laboratory of Dr K.F. Austen was low: in contrast to a normal level of $2 \cdot 14 \pm 0.87 \mathrm{mg} / \mathrm{ml}$ the patient's level was $0.3 \mathrm{mg} / \mathrm{ml}$, the father's was $0.1 \mathrm{mg} / \mathrm{ml}$; the patient's sister and both children had normal levels.

\section{Case 2}

E.V., a 46-year-old housewife, has a long history of recurring abdominal pain and oedema. Since her early teens she has noted intermittent localized oedema of the limbs, trunk, neck, and face. This has been neither painful, pruritic, red, nor hot, and usually lasts two or three days before abating completely. Oedema is unrelated to any activity, food intake, position, medication, time of day, season, or emotional state. Local trauma has been noted on occasion to result in a mild attack. There has been no pattern of frequency, episodes coming from two or three weeks to several months apart. Medication has never had any effect on the course of the oedema. She has not at any time suffered from pharyngeal or laryngeal oedema.

The patient has also had intermittent abdominal pain since childhood, the onset of the abdominal pain preceding the onset of the re-

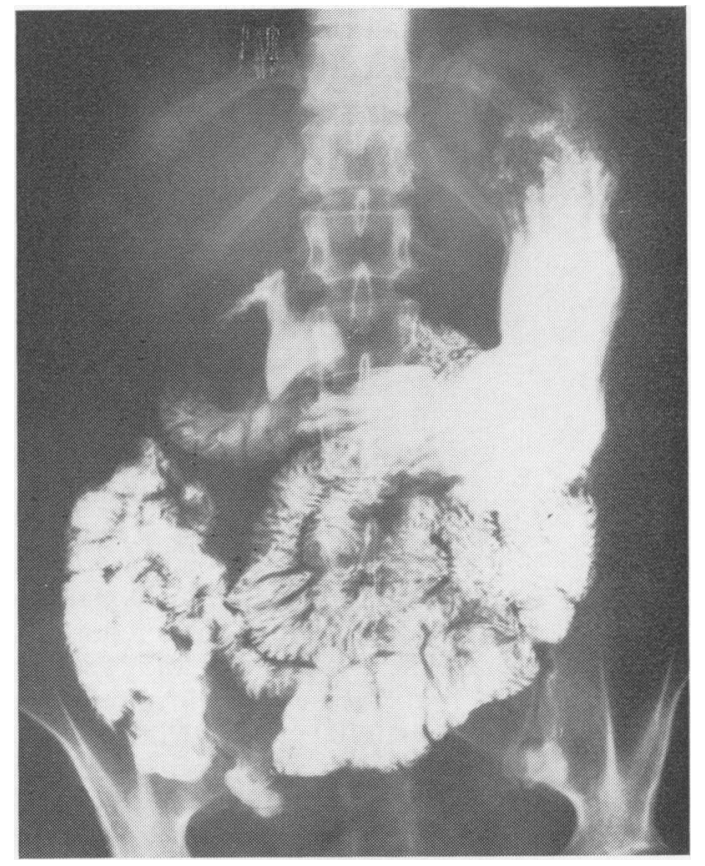

Fig. 2 Repeat examination after the episode had ended demonstrating complete resolution of the oedema. 
curring oedema by several years. The pain varies in character and location, but is always well localized during a particular attack. Marked nausea and vomiting accompany the pain, but diarrhoea is rare. The episodes last 12 to 36 hours before spontaneously abating, and are accompanied by severe prostration and anxiety. Physical examination during these episodes has been consistently normal, the abdomen always being described as soft, without rigidity, rebound tenderness, or guarding despite severe local tenderness. As with the oedema, she is unable to relate the pain to any specific precipitating cause, and likewise no specific treatment other than narcotics has given relief. She has never found any relationship between the oedema and the abdominal pain.

The patient has been admitted to hospital many times, the first when she was 12 when she underwent an appendectomy. Between 1953 and 1968 she was admitted 20 times and has undergone numerous other surgical procedures including, in order, ovarian cystectomy, cholecystectomy, hysterectomy with oophorectomy, and exploratory laporotomy. Extensive chemical, haematological, and pathological evaluation has likewise been unrevealing. Diagnoses have, at different times, included pancreatitis, cholecystitis, common duct stone, ruptured ovarian cyst, renal stone, pyelonephritis, intestinal obstruction, duodenal ulcer, and ulcerative colitis. During one admission it was concluded that she represented a 'classic example of abdominal hysteria'.

Several aspects of her hospitalizations are of interest. In June 1954 at cholecystectomy the operative note describes 'oedema in the hepaticoduodenal ligament as well as oedema of the fat overlying the pancreas with a normal pancreas beneath'. No gallstones were found. In November 1954, while pregnant, she developed mild hypertension, proteinuria, and oedema. The oedema was unusual and she was felt to have an 'allergic component to toxaemia'. She spontaneously aborted in her sixth month. In July 1959 during an episode of severe lower abdominal pain she was noted to have bulging in the right cul-de-sac. A culdocentesis removed $250 \mathrm{ml}$ of clear yellow fluid and the pain was instantly relieved. In December 1954, one day after a severe episode of vomiting, diarrhoea, and abdominal pain, she developed a pleural effusion, fever, chest pain, and haemoptysis which were then considered to represent a pulmonary embolism. Marked haemoconcentration was present on admission, an initial haematocrit of $61 \%$ falling to $40 \%$ within two days.

The patient first came to our attention in 1969 when her brother was being studied for hereditary angioneurotic oedema because of his long history of abdominal pain and characteristic oedema. By arrangement the patient was admitted to the hospital in April 1969 early in the course of an attack of abdominal pain. Radiographic study of the upper gastrointestinal tract was performed immediately upon admission and showed evidence of marked duodenal oedema. Within the first hour only a small amount of contrast material passed the pylorus. A Quentin-Rubin small-bowel biopsy tube would not pass the pylorus during the acute stage. Three days later, with the patient asymptomatic, a repeat barium study was completely normal and the biopsy tube passed readily. At this time the small bowel mucosa was seen to be histologically normal by light and electron microscopy. Routine laboratory studies were also completely normal. The diagnosis was confirmed by the demonstration in Dr V. Donaldson's laboratory of low levels of $C^{\prime} 1$ esterase inhibitor. The patient's family history and a table of the levels of inhibitor in each is given in Figure 3 and the Table.

\begin{tabular}{lll}
\hline Patient & Symptoms & $\begin{array}{l}\text { Inhibitor (units/ml) } \\
(N=5 \cdot 8 \pm 1 \cdot 8)\end{array}$ \\
\hline II-1 & No & $5 \cdot 7$ \\
II-2 & Yes & 0 \\
II-5 & Yes & 0 \\
III-1 & No & $6 \cdot 8$ \\
III-2 & No & $8 \cdot 1$ \\
III-3 & Yes & 0 \\
III-4 & No & $10 \cdot 6$ \\
III-5 & No & $7 \cdot 8$ \\
III-6 & Yes & 0 \\
III-7 & No & $6 \cdot 6$ \\
III-8 & Yes & 0 \\
\hline
\end{tabular}

Table $C^{\prime} 1$ esterase inhibitor levels in the family of case 2 (see Fig. 3).

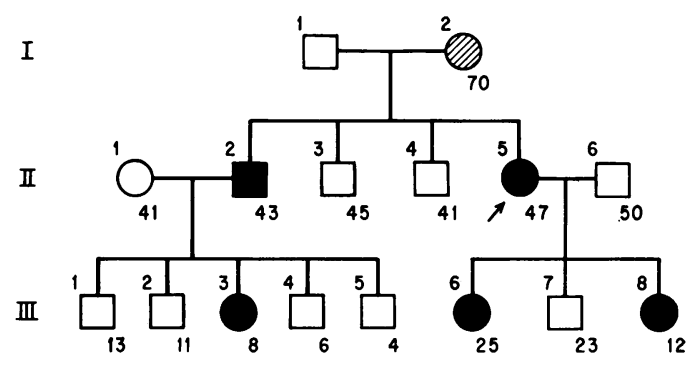

Fig. 3 Pedigree of patient 2.

Key: $\square, \bigcirc=$ normal male, female. $\square, 0=$ diagnosed hereditary angioneurotic oedema. = historical evidence of angioneurotic oedema. The arrow indicates the proband. A superscript indicates the position in the pedigree, and subscript the patient's age.

\section{Discussion}

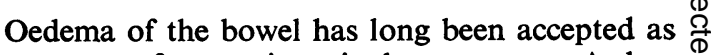
a cause of gastrointestinal symptoms. A low $\varrho$ plasma oncotic pressure, local inflammation, and local allergens may all lead to intestinal oedema. $\delta$ The hereditary form represents only a small fraction of these, but it is specific and it is important to recognize it. 
BIOCHEMICAL ASPECTS

A specific biochemical defect underlies the condition. The complement system is a complex group of proteins involved in immune reactions and reacting via a 'cascade' system (Schur and Austen, 1968). The first component of this reaction exists in a precursor form in plasma (Naff, Pensky, and Lepow, 1964). Upon interacting with an antigen-antibody complex it is activated to $C^{\prime} 1$ esterase (C'1a) (Donaldson and Evans, 1963). In vivo this enzyme has as its natural substrates other parts of the complement chain, complement-2 ( $\left.C^{\prime} 2\right)$ and complement-4 $\left(C^{\prime} 4\right)$ (Becker, 1960). In vitro the esterase act on several synthetic organic esters, the most specific being $\mathrm{N}$-acetyl-1tyrosine ethyl ester (Haines and Lepow, 1962): a method of detection and quantitation is based on this latter substrate (Levy and Lepow, 1959). An inhibitor to $C^{\prime} 1$ esterase is normally present in the serum and acts to maintain low levels of $\mathrm{C}^{\prime} 1 \mathrm{a}$ in the 'resting' state and to reduce elevated levels during reactions involving the complement chain. Persons with hereditary angioneurotic oedema lack this inhibitor activity and, consequently, abnormally high levels of active $C^{\prime} 1$ are found in the plasma (Donaldson and Evans, 1963), and the natural substrates of $C^{\prime} 1$ esterase $\left(C^{\prime} 2\right.$ and $\left.C^{\prime} 4\right)$ are found in decreased concentrations (Austen and Sheffer, 1965). In most persons with hereditary angioneurotic oedema not only is the inhibitor reduced in activity when measured chemically but it is also reduced in amount when measured immunologically. A small group of patients, however, show normal levels of proteins to immunological study but the protein is chemically inactive (Rosen, Charache, Pensky, and Donaldson, 1965).

The mechanism whereby biochemical changes effect oedema is not yet completely understood. $C^{\prime} 1$ esterase increases vascular permeability in both man and guinea pig (Ratnoff and Lepow, 1963; Burdon, Queng, Thomas, and McGovern, 1965): the active particle is a small polypeptide released from $C^{\prime} 2$ by the action of $C^{\prime} 1$ esterase (Klemperer, Rosen, and Donaldson, 1969). This polypeptide is probably unrelated to bradykinin (Donaldson, Ratnoff, da Silva, and Rosen, 1969) and increases vascular permeability by a mechanism different from that of histamine (Klemperer, Donaldson, and Rosen, 1968). That $C^{\prime} 2$ is the source of the active particle is supported by the finding that persons with an hereditary absence of $C^{\prime} 2$ show a markedly diminished increase in permeability when tested with $C^{\prime} 1$ esterase compared with normals (Klemperer, Austen, and Rosen, 1967).

Systems other than complement may play a role in hereditary angioneurotic oedema. PF/dil, a permeability factor generated when salinediluted plasma comes in contact with a glass surface (Miles and Wilhelm, 1955), may be elevated in affected patients (Landerman et al, 1962). Other abnormalities have included a de- crease in the levels of plasma kallikrein inhibitor, a substance inhibiting the conversion of an alpha-2 globulin precursor, kininogen, into a vasoactive polypeptide, kinin (Landerman et al, 1962). It has been suggested that kallikrein and $\mathrm{PF} /$ dil may participate in events leading to the initial activation of $C^{\prime} 1$ (Donaldson, 1968). Supporting this is the finding that the inhibitor of $C^{\prime} 1$ esterase also acts to inhibit PF/dil and kallikrein (Kagen and Becker, 1963). Such a concept would lend some unity to these isolated observations on some of the factors involved in the initiation, spread, and regression of the oedema.

\section{HISTOLOGICAL ASPECTS}

That the bowel is oedematous during acute attacks has long been known: a specimen of pyloric mucosa recovered during a gastric analysis in 1904 showed marked mucosal and submucosal oedema (Morris, 1904). Electron micrographic study of a small-bowel biopsy specimen taken from the brother of case 2 while he was having a mild attack of abdominal pain showed marked dilatation of the intercellular spaces along the lateral borders of the cells (Fig. 4). The significance of this finding is not clear. It may represent fluid transport (Kaye, Wheeler, Whitlock, and Lane, 1966) but neither direction nor flow rate can be determined from the specimen. The dilated spaces are not fixation artifacts, as other biopsies processed in the same laboratory by identical techniques have not shown this finding. Light microscopic examination of the same section showed only mild oedema of the lamina propria.

\section{CLINICAL ASPECTS}

Each patient has a characteristic history and findings. The onset of symptoms is usually in late childhood, but may vary from infancy (Wason, 1926) to the late 50s (Thorvaldsson, Sedlack, Gleich, and Ruddy, 1969). The episodes of localized oedema usually occur suddenly, with little warning. The areas are hard, seldom painful or pruritic, and often are sharply demarcated from adjacent normal tissue. They are pale, rarely red, and usually cool to touch. They are tense, but do not pit. Although the oedema may involve all parts of the body, the face, limbs, and trunk are most often involved. In children a curious, self-limited, rapidly abating, red mottling of large areas of skin may precede by years the development of other symptoms (Donaldson and Rosen, 1966). Although the cutaneous oedema is localized, self-limiting, and not harmful, oedema of the larynx is unfortunately common and often lethal. Although no proof is available, patient 2 had four uncles who died of 'asthma' in childhood, all of whom may well have succumbed to laryngeal oedema.

The recurrent severe abdominal pain often represents a diagnostic dilemma, particularly when 


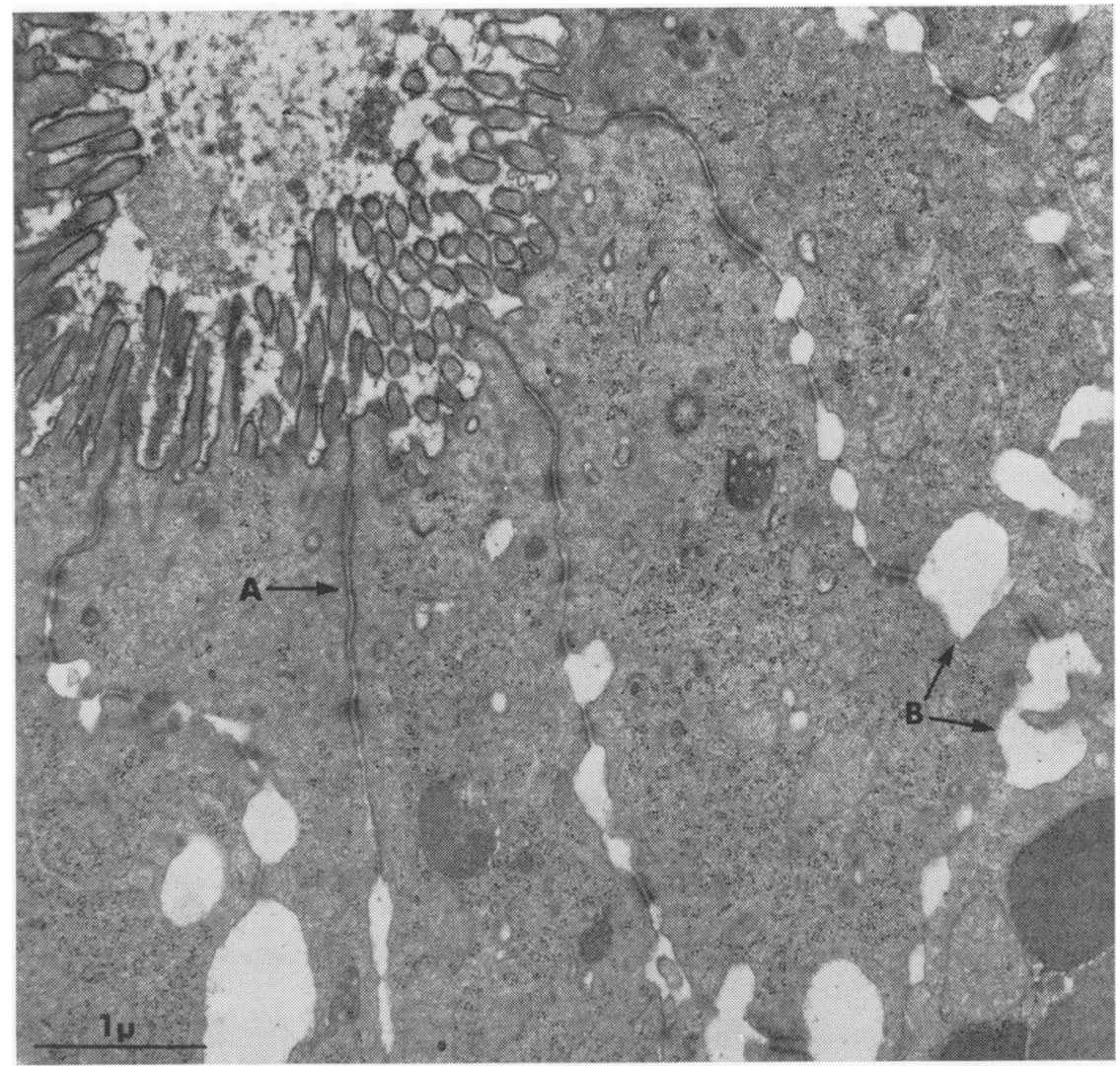

Fig. 4 Electron micrograph of crypt cells of the small bowel showing intercellular oedema in a patient with hereditary angioneurotic oedema. A represents a normal intercellular space and B collections of fluid within these spaces.

it precedes the onset of the oedema by several years. Occasionally, patients may suffer only from abdominal pain, oedema never occurring (Sheldon, Schreiber, and Lovell, 1949; Biering, 1956; Landerman, 1962). The absence of an obvious family history of the disorder is not always helpful. Relatives may have only mild symptoms, may never have sought medical treatment, or may be asymptomatic despite low levels of $C^{\prime} 1$ esterase inhibitor (Donaldson and Rosen, 1966). Presumably in some patients hereditary angioneurotic oedema may arise as a mutation, both parents having normal levels of inhibitor (Lundh, Laurell, Wetterqvist, White, and Granerus, 1968). The patient may further complicate the diagnostic problem by failing to mention episodes of oedema if they are not connected with the pain.

Pain may be present anywhere in the abdomen and may mimic many other abdominal disorders. As might be expected, the pain pattern varies with the location of the oedema which has been described in the caecum, small bowel, retroperitoneal space, urinary system, and elsewhere (Blaustein, 1926; Biering, 1956). In our second patient, pelvic oedema seems clearly to have been present. Through the gastroscope during an attack of severe epigastric pain, striking oedema of the gastric mucosa has been observed which, three days later, returned completely to normal (Lundbaek, 1940). In one report '... a uterus which in thirty minutes presented above the pelvis as large and to the touch very much the appearance of a twenty-pound cannon ball ...' is described (Crowder and Crowder, 1917). During an attack the abdomen, although locally tender, is soft, with no rigidity or guarding and usually normal bowel sounds are present. Laboratory data are usually normal with no eosinophilia. On occasion marked intravascular dehydration has led to a haematocrit as high as $70 \%$ (Donaldson and Rosen, 1966).

The diagnosis can be difficult and the recurrent abdominal pain often provokes unnecessary surgery, a fact unfortunately well demonstrated in both the present patients. The radiological demonstration of intestinal oedema, as shown in Fig. 1, can be very helpful only when the examination is done while the patient is still symptomatic. Too often, however, the contrast study is delayed a day or two until the acute episode 'stabilizes' and such a delay permits resolution of the oedema so that the diagnosis is missed, as shown by the multiple negative radiological studies in both our patients.

Treatment is unsatisfactory. Methylesto- 
sterone has been proposed for the prevention of frequent attacks (Spaulding, 1960) and some have had intermittent success using it (Donaldson and Rosen, 1966). Epsilon amino caproic acid has likewise been used for prophylaxis with mixed results (Lundh et al, 1968). Neither drug has any effect once an attack has begun. Obviously, the episodic nature of the disorder makes evaluation of any agent quite difficult. Fresh frozen plasma has recently been successfully used to abort acute episodes in two patients, one with abdominal pain and the other with laryngeal oedema (Pickering, Kelly, Good, and Gewurz, 1969). The infusion elevated the level of $C^{\prime} 1$ esterase inhibitor in the recipients' plasma. Plasma given early might aggravate rather than ameliorate an attack by supplying additional substrate as well as inhibitor (Rosen and Austen, 1969). The risk of infusion of plasma must be considered when treating a self-limiting non-fatal complication. The treatment of laryngeal oedema, however, may well require plasma infusion.

We should like to thank Drs K. F. Austen, V. H. Donaldson, and F. R. Rosen for the $C^{\prime} 1$ esterase inhibitor analyses, and Drs A. M. Stein, C. E. Arbesman of Buffalo, N.Y, and Dr D. R. Sokhos of New Haven, Conn, for referring their patients to us. The electron micrography was done by Miss Lillemor Wallmark and Dr Raymond Yesner.

\section{References}

Austen, K. F., and Sheffer, A. L. (1965). Detection of hereditary angioneurotic edema by demonstration of a reduction in the second component of human complement. New Engl. J. Med., 272 649-656.

Barnett, A. F. (1948). Hereditary angioneurotic edema; a remarkable family history. Calif. Med., 69, 376-380.

Becker, E. L. (1960). Concerning the mechanism of complement action. V. The early steps in immune hemolysis. J. Immunol., 84, 299-308.

Biering, A. (1956). Abdominal pains in angioneurotic edema. Acta med. scand., 153, 373-382.

Blaustein, N. (1926). Angioneurotic edema of the entire genitourinary system. $J$. Urol., 16, 379-390.

Burdon, K. L., Queng, J. T., Thomas, O. C., and McGovern, J. P. (1965). Observations on biochemical abnormalities in hereditary angioneurotic edema. J. Allergy, 36, 546-557.

Crowder, J. R., and Crowder, T. R. (1917). Five generations of angioneurotic edema. Arch. intern. Med., 20, 840-852.

Donaldson, V. H. (1968). Mechanisms of activation of $C^{\prime} 1$ esterase in hereditary angioneurotic edema plasma in vitro. The role of Hageman factor a clot-promoting agent. J. exp. Med., 127, 411-429.

Donaldson, V. H., and Evans, R. R. (1963). A biochemical abnormality in hereditary angioneurotic edema. Absence of serum inhibitor of C'1-esterase. Amer. J. Med., 35, 37-44.

Donaldson, V. H., Ratnoff, O. D., da Silva, W. D., and Rosen, F. S. (1969). Permeability-increasing activity in hereditary angioneurotic edema plasma. II. Mechanism of formation and partial characterization. J. clin. Invest., 48, 642-653.

Donaldson, V. H., and Rosen, F. S. (1966). Hereditary angioneurotic edema: a clinical survey. Pediatrics, 37, 1017-1027.
Haines, A. L., and Lepow, I. H. (1962). Studies on human C'1esterase. I. Purification and enzymatic properties. $J$. Immunol., 92, 456-467.

Kagen, L. J., and Becker, E. L. (1963). Inhibition of permeability globulins by C'1 esterase inhibitor. Fed. Proc., 22, 613.

Kaye, G. I., Wheeler, H. O., Whitlock, R. T., and Lane, N. (1966). Fluid transport in the rabbit gallbladder. A combined physiological and electron microscopic study. J. Cell. Biol., 30, 237-268.

Klemperer, M. R., Austen, K. R., and Rosen, F. S. (1967) Hereditary deficiency of the second component of complement $\left(C^{\prime} 2\right)$ in man: further observations on a second kindred. J. Immunol., 98, 72-78.

Klemperer, M. R., Donaldson, V. H., and Rosen, F. S. (1968). Effect of $C^{\prime} 1$ esterase on vascular permeability in man: studies in normal and complement-deficient individuals and in patients with hereditary angioneurotic edema. J. clin. Invest., 47, 604-611.

Klemperer, M. R., Rosen, F. S., and Donaldson, V. H. (1969). A polypeptide derived from the second component of human complement $\left(C^{\prime} 2\right)$ which increases vascular permeability. J. clin. Invest., 48, 45a.

Landerman, N. S. (1962). Hereditary angioneurotic edema. I. Case reports and review of the literature. J. Allergy, 33, 316-329.

Landerman, N. S., Webster, M. E., Becker, E. L., and Ratcliffe, H. E. (1962) Hereditary angioneurotic edema. II. Deficiency of inhibitor for serum globulin permeability factor and/or plasma kallikrein. J. Allergy, 33, 330-341.

Levy, L. R., and Lepow, I. H. (1959). Assay and properties of serum inhibitor of $\mathrm{C}^{\prime} 1$ esterase. Proc. Soc. exp. Biol. (N.Y.), 101, 608-611.

Lundbaek, K. (1940). Gastroscopically verified oedema of the stomach in a case of familial Quincke's disease. Gastroenterologia (Basel), 65, 129-136.

Lindh, B., Laurell, A. B., Wetterqvist, H., White, T., and Granerus, G. (1968). A case of hereditary angioneurotic oedema, successfully treated with $\epsilon$-aminocaproic acid. Studies on $C^{\prime} 1$ esterase inhibitor, $C^{\prime} 1$ activation, plasminogen level and histamine metabolism. Clin. exp. Immunol., 3, 733-745.

Miles, A. A., and Wilhelm, D. L. (1955). Enzyme-like globulins from serum reproducing the vascular phenomenon of inflammation. I. An activable permeability factor and its inhibitor in guinea-pig serum. Brit. J. exp. Path., 36, 71-81.

Morris, R. S. (1904). Angioneurotic edema. Report of two cases with the histology of a portion of the gastric mucosa obtained by thestomach tube. Amer.J. med. Sci., 128, 812824.

Naff, G. B., Pensky, J., and Lepow, I. H. (1964). The macromolecular nature of the first component of human complement. J. exp. Med., 119, 593-614.

Osler, W. (1888). Hereditary angioneurotic oedema. Amer. J. Med. Sci., 95, 362-367.

Pickering, R. J., Kelly, J. R., Good, R. A., and Gewurz, H. (1969). Replacement therapy in hereditary angioedema. Successful treatment of two patients with fresh frozen plasma. Lancet, 1, 326-330.

Quincke, H. (1882). Úber akutes umschriegenes Hautodem. Mh. prakt. Derm., 1, 129.

Ratnoff, O. D., and Lepow, I. H. (1963). Complement as a mediator of inflammation. Enhancement of vascular permeability by purified human $\mathrm{C}^{\prime} 1$ esterase. J. exp. Med., 118, 681-698.

Rosen, F. S., and Austen, K. F. (1969). The "neurotic edema" (hereditary angioedema). New Engl. J. Med., 280, 13561357.

Rosen, F. S., Charache, P., Pensky, J., and Donaldson, V. (1965) Hereditary angioneurotic edema; two genetic variants. Science, 148, 957-958.

Schur, P. H., and Austen, K. F. (1968). Complement in human disease. Ann. Rev. Med., 19, 1-24.

Sheldon, J. M., Schreiber, E. O., and Lovell, R. G. (1949). Hereditary angioneurotic edema with a case report. J. Lab. clin. Med., 34, 524-530.

Spaulding, W. B. (1960). Methyltestosterone therapy for hereditary episodic edema (herediatry angioneurotic edema). Ann. intern. Med., 53, 739-745.

Thorvaldsson, S. E., Sedlack, R. F., Gleich, G. J., and Ruddy, S. J. (1969). Angioneurotic edema and deficiency of $C^{\prime} 1$ esterase inhibitor in a 61 year old woman. Ann. intern. Med., 71, 353-357.

Wason, I. M. (1926). Angioneurotic edema-report of a case with necropsy findings. J. Amer. med. Ass., 86, 1332-1333. 